\title{
Technological Development of Russia: HR Policy, Digital Transformation, Industry 4.0
}

\author{
A. V. Olisaeva \\ North Ossetian State University after K. L. Khetagurov \\ Vladikavkaz, Russia \\ alisa.olisaeva@mail.ru
}

\begin{abstract}
The article discusses the technological development of Russia in terms of personnel policy, digital transformation of the economy, and the promotion of Industry 4.0. The perspective directions of economic development are considered: personnel and education; formation of research competencies and technical groundwork; information infrastructure, exchange of technology and theoretical knowledge.
\end{abstract}

Keywords - digital transformation; personnel; education; Industry 4.0; quality of life; priority sectors of the economy

\section{INTRODUCTION}

The basis for the development of public administration, business, the social sphere and society at the present stage is the digital economy, capable of ensuring national security and independence of Russia, as well as providing new opportunities for citizens of the country.

Digital transformation is taking place on a global level, and for Russia it is an inevitable and urgent process, which is mentioned at the highest level of the country in the form of the terms "robotics", "artificial intelligence", "unmanned vehicles", "electronic commerce", "big data processing technologies", "Fifth generation data networks", "Internet of things communications technology".

Digital technologies are becoming more multifaceted every day and are more active in all areas of our lives. The true digital revolution has already embraced both small and large businesses. Behind the technological breakthrough of companies is the future of the economy. Russian industry also intends to rely on digital transformation. Breakthrough developments in areas such as artificial intelligence, nanotechnology and others lead not only to the creation of new market segments, but also to a radical change in existing business models. The combination of increased Internet penetration, mobile devices, the development of data analysis, the "Internet of things" and machine learning is changing the expectations and demands of consumers. The integration of these technologies into the business and operational model is not a competitive advantage, but a necessary condition.

An integrated approach of state policy in the field of transition to digital platforms will undoubtedly contribute to a technological breakthrough, which in turn will have a huge effect both for business and for the competitive advantages of the country's economy as a whole. The ongoing changes will automate most of the processes and focus the state's human resources on change management. In the coming decades, automation will have a significant impact on the labor market, and digital platforms will create new employment opportunities and increase labor productivity.

The Ministry of Industry and Trade of the Russian Federation presented a model of digital transformation of industry, which includes three areas:

1. digital transformation of manufacturing industries;

2. creation, integration and development of platforms of the state industry information system (GISP);

3. creation a regulatory environment for digital transformation of industry.

The creation of GISP will allow the development of the following platforms:

- platform for effective investment in industry;

- platform for the creation and development of production of industrial enterprises;

- a platform for selecting a set of government support measures, their receipt and monitoring the achievement of project performance indicators;

- $\quad$ platform for the production and promotion of industrial products in the domestic market;

- platform for promoting products on the foreign market, increasing export volumes;

- platform for the analysis and forecast of production development based on objective statistical data.

These services will improve the current state of GISP in the amount of 150 thousand users - an active GISP audience, up to 268 functional interaction services G2G, B2G and B2B.

\section{RESULTS}

Global trends in the development of digital technologies affect the international community directly or indirectly, since the growth of labor productivity in one country (company) widens the gap between participants, reducing the competitiveness of other, technologically lagging countries and companies. "The creation of systems for processing large amounts of data, machine learning and artificial intelligence" 
along with the transition to advanced digital, intelligent manufacturing technologies, robotic systems, new materials and design methods is considered by the Strategy for Scientific and Technological Development of the Russian Federation as the main technologies for innovative development that ensure timely response RF on the big challenges of global change. [5]

Digital transformation is a factor in global economic growth. According to analytical studies, Russia's digitalization will increase GDP by 2025 to 9 trillion rubles [4]. This fact may be affected by:

- digital platforms;

- digital ecosystems;

- deep analytics of large data arrays;

- Technology Industry 4.0.

Digitalization contributes to a sharp increase in labor productivity. On November 1, 2018, President V.V. Putin held a meeting in the Kremlin with an asset of the Eastern Committee of the German Economy, representatives of the largest German enterprises - top managers of the largest companies such as Siemens, Volkswagen, Knauf, Daimler and others. During the meeting, the Russian president told them about the digital economy program in Russia, and the German side, in turn, expressed interest in developing joint initiatives in this area. Putin said that much is being done in Russia for the country's dynamic technological development. The Digital Economy program has been launched, within the framework of which it is planned to increase labor productivity by $30 \%$ by 2024.

The concept of "Industry 4.0" was created in Germany, therefore, cooperation with representatives of the world economy will allow us to adapt the scenarios of "Industry 4.0" to the Russian specifics. The German-Russian Economy Digitalization Initiative (GRID) brings together commercial and public sectors in the digital economy and industry 4.0. The main objective of the initiative is the introduction of the best European practices in the fields of digitalization and innovation in the Russian economy in order to increase its competitiveness. The exchange of experience between participants in the digital field will also help improve the quality of German-Russian products and increase their market share.

Thus, the joint interaction allows us not only to accelerate the development of innovative technologies in Russia, but also allows us to reduce the time from development to the introduction of innovations in production, which gives impetus for further development in all areas. That is why global partnerships and innovations are of particular importance. In this regard, GRID is an effective tool for adapting best practices in the field of digitalization of the economy.

Companies that have successfully implemented the Industry 4.0 concept no longer have to choose between higher gross revenues and higher profits - they can improve both indicators simultaneously. The concept of "Industry 4.0" will lead to the formation of a new competitive environment and radical changes in traditional industries.
A key institution in the digital economy is the renewal and development of the personnel of the education system. According to the Rosstat demographic forecast, the population will decrease, and automation will mitigate the consequences of this process, and digitalization will help improve the quality of life of citizens. In these conditions, "digital" personnel are a strategic asset of the state.

The Russian Federation is not yet one of the leaders in digitalization, but managed to create large digital companies that have achieved fame. These include: MailRu Group, Yandex, Kaspersky Lab, and many others. The digital economy in the leading countries accounts for $10.9 \%$, while in the Russian Federation only 5\% of GDP. Obviously, the challenge is to double the digital economy in the Russian Federation.

However, the digital economy of the Russian Federation is characterized by digital inequality - imbalances between regions in the development of digital technologies. But at the same time, the country has a fairly well-developed ICT infrastructure, and digital services are available to most of the population.

In June 2019, the Analytical Center under the Government of the Russian Federation published an analytical report "Current Development of Projects in the Field of Digital Economy in the Russian Regions". [5]

The survey showed information on the needs of the regions in digital technology. Data on the priority sectors of digital transformation is necessary for the effective implementation of support measures for the introduction of digital technologies in the economic and social sectors in Russia.

The analytical center conducted a survey of regional executive authorities (ROIV) of Russia. Information was requested about:

- the existence of a regional program for the development of the digital economy;

- $\quad$ priority for the region end-to-end digital technologies (SCT), planned for implementation;

- priority sectors for the region in which the first implementation of digital technologies is planned;

- a landmark project for the region in the field of the digital economy, which is under implementation or has been implemented.

A prerequisite for the digitalization of industries is to achieve a high level of informatization and automation. On this basis, the regions, in addition to programs and projects in the field of the digital economy, also indicated programs and projects in the field of developing information infrastructure and implementing automated information systems (AIS).

Based on the results of the survey conducted from April 30, 2019 to May 17, 2019, responses were received from 79 constituent entities of the Russian Federation:

- in 34 regions, a regional digitalization program has been developed or is under development; 
- 45 regions participating in the survey reported that there is no regional digitalization program and the development process has not begun.

Most of the regional projects in the field of the digital economy are being implemented in areas similar to the federal projects of the national program "Digital Economy":

- Information Security;

- information infrastructure;

- digital technology;

- normative regulation of the digital environment;

- $\quad$ personnel for the digital economy;

- digital government.

As a priority for the implementation of SCT, most regions noted big data ( $80 \%$ of the regions surveyed) and wireless technology $(63 \%)$. Also popular industry centers included the industrial Internet and the Internet of things (53\%), neurotechnologies and artificial intelligence (47\%), distributed registry systems (43\%), virtual and augmented reality technologies $(30 \%)$, new production technologies $(28 \%)$ and components of robotics and sensorics (27\%). Also, the following SCT and subtechnologies were noted as priorities by a number of regions: quantum technologies, cloud technologies, technologies for secure information interaction, predictive analytics. It is also worth noting that regions active in the digital economy (Moscow, the Republic of Tatarstan and Bashkortostan) are characterized by the choice of a variety of SCTs with a significant number of areas of digitalization.

The range of spheres and industries that the regions chose as priority for the implementation of digital technologies is quite wide, so for some of them enlarged groups have been formed. For most regions, priority areas and sectors are:

- healthcare (75\% of the regions);

- urban environment (75\% of regions);

- $\quad$ personnel and education (66\% of the regions);

- transport and communications, including wireless and digital mobility ( $61 \%$ of the regions);

- Housing and utilities and energy (56\% of the regions).

Also, the regions identified agriculture and forestry, culture and tourism, state and municipal services and management (including digital government), construction and industry as priority sectors.

Russia's readiness is reflected in the development of wireless technologies and broadband Internet in almost the entire territory of the country. It should be noted that the Russian Federation is a pioneer in the development of the next generation of $5 \mathrm{G}$ mobile communications, which is a new opportunity for developing user services and connecting more devices. 5G will allow you to connect a large number of different devices to the mobile network - from household appliances to industrial equipment. Massive machine communications will be used in projects of a "smart" city, a "smart" home, and other intelligent monitoring systems. 5G will also allow performing remote medical diagnostics and performing surgical operations remotely, remotely control production equipment, control drones in scenarios most sensitive to data transmission delays, etc. 5G technologies are needed to implement the most futuristic services, such as:

- remotely controlled production equipment;

- $\quad$ tactile Internet - remote medical diagnostics, surgical operations using robots, etc.

- fully functional automated transport system;

- drone control in scenarios that are most sensitive to data transmission delay. [6]

All leading countries are working to create public policy to stimulate the deployment of next-generation networks, recognizing their strategic importance for acquiring national technological leadership on the world stage.

Digital technologies make it possible to launch the mechanism of socialization in such areas as comfortable and safe cities, an increase in the number of highly skilled specialists, and an improvement in the business and investment climate.

At the state level, promising directions for the development of digitalization are: reforming the educational infrastructure, financing applied research and digital entrepreneurship, retraining and additional education, addressing the priority tasks of digital development of industries, developing digital infrastructure, and actively promoting it, exchange not only technologies and theoretical knowledge, but directly the experience of introducing innovations, optimizing them for the needs of the economy and building new ecosystems.

The opportunities for transforming the digital economy are also being transferred to companies in such areas of development as: developing a culture of innovation and mastering new technologies, using the world experience of the most successful companies, mastering the technology Industry 4.0., Cooperation with other participants in the digital ecosystem, creation of "digital universities" on the basis of companies. The labor market is changing and requires that specialists have not only the most advanced competencies, but also that there are many. Everyone should have both practical skills and knowledge - this will allow them to find their place and receive decent wages. That is why the development of new professional standards and methods for training specialists at various levels, taking into account the international experience of WorldSkills, becomes especially urgent.

In Russia, there is an urgent need to invest in the national economy, to adapt and introduce modern technology. Leading positions can be taken only with the cooperation of the state, business, constant interaction with technological and scientific communities and external partners.

\section{REFERENCES}

[1] "Strategy for the development of the information society in the Russian Federation for 2017 - 2030" approved by the decree of the President of the Russian Federation dated 05.09.2017 No. 203. Electronic source. ATP Consultant Plus (appeal date: 07/22/2019). (In Russian) 
[2] The program "Digital Economy of the Russian Federation." Approved by order of the Government of the Russian Federation dated July 28, 2017 No. 1632-r [Electronic resource] - Access mode: http://static.government.ru/media/files/9gFM4FHj4PsB79I5v7yLVuPgu 4bv R7M0.pdf (accessed: 08.08.2019). (In Russian)

[3] The action plan in the direction of "Normative regulation". Appendix No. 1 to the minutes of the meeting of the Government Commission on the use of information technology to improve the quality of life and the conditions for doing business on December 18, 2017 No. 2. Electronic source // ATP Consultant Plus (accessed: June 2, 2019). (In Russian)

[4] Aptekman A., Kalabin V., Klintsov V., Kuznetsova E., Kulagin V., Yasenovets I. Digital Russia: a new reality. Digital/McKinsey. LLC McKinsey and Company CIS Publ., 2017. (In Russian)

[5] Analytical report "Current development of projects in the field of the digital economy in the regions of Russia." Analytical Center under the Government of the Russian Federation http://ac.gov.ru/ (In Russian)

[6] 5G in Russia: Prospects, approaches to the development of the standard and networks. Study review / www.pwc.ru (accessed: 08/02/2019) (In Russian)

[7] Olisaeva A., Dzobelova V., Yablochnikov S., Cherkasova O., Davletbayeva N. FORMATION AND DEVELOPMENT OF THE DIGITAL ECONOMY IN MODERN
DEVELOPMENT WITHIN THE FRAMEWORK OF INDUSTRY 4.0. IDIMT-2019. Innovation and Transformation in a Digital World TRAUNER Druck GmbH \& Co KG, Linz, 2019. C. 83-88.

[8] Dzobelova VB, Olisaeva A.V. DEVELOPMENT OF PERSONNEL NEEDS OF THE REGIONAL ECONOMY IN MODERN CONDITIONS OF THE LABOR MARKET. Planirovanie $i$ obespechenie podgotovki kadrov dlya promyshlenno-ekonomicheskogo kompleksa regiona [Planning and providing training for the industrial and economic complex of the region]. 2018.V. 1.P. 201-204. (In Russian)

[9] Rysin Y.S., Terekhov A.N., Yablochnikov S.L., Ievlev O.P., Dzobelova V.B. ON THE ISSUE OF SPEAKER'S IDENTIFICATION IN COMMUNICATION NETWORKS AND TERMINAL EQUIPMENT OF ONBOARD SYSTEM 2019 Systems of Signals Generating and Processing in the Field of on Board Communications, SOSG 20192019. C. 8706759 .

[10] Dzobelova V.B., Olisaeva A.V. STAFFING NEEDS IN THE REGIONAL ECONOMY UNDER THE MODERN CONDITIONS OF LABOR MARKET. Proceedings of 2018 17th Russian Scientific and Practical Conference on Planning and Teaching Engineering Staff for the Industrial and Economic Complex of the Region, PTES 201817. 2018. C. $185-188$ 